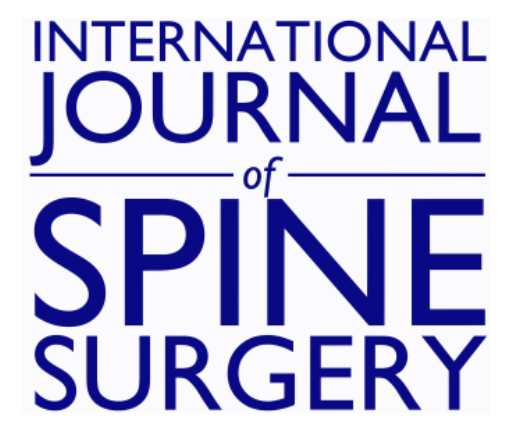

\title{
Viscoelastic Disc Arthroplasty Provides Superior Back and Leg Pain Relief in Patients with Lumbar Disc Degeneration Compared to Anterior Lumbar Interbody Fusion
}

Burkhard Rischke, Kari B. Zimmers and Eric Smith

Int J Spine Surg 2015, 9 ()

doi: https://doi.org/10.14444/2026

http://ijssurgery.com/content/9/26

This information is current as of April 26, 2023.

Email Alerts Receive free email-alerts when new articles cite this article. Sign up at:

http://ijssurgery.com/alerts

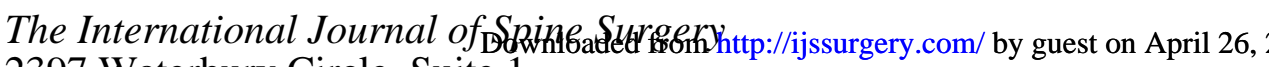
2397 Waterbury Circle, Suite 1,

Aurora, IL 60504, Phone: +1-630-375-1432

(C) 2015 ISASS. All Rights Reserved. 


\section{Viscoelastic Disc Arthroplasty Provides Superior Back and Leg Pain Relief in Patients with Lumbar Disc Degeneration Compared to Anterior Lumbar Interbody Fusion}

Burkhard Rischke, MD, PhD, ${ }^{1}$ Kari B. Zimmers, BS, 2 Eric Smith, $B S^{2}$

${ }^{1}$ Center of Excellence for Dynamic Spine Arthroplasty, Zürich, Switzerland, ${ }^{2}$ AxioMed LLC, Garfield Heights, Ohio, USA

\section{Abstract}

\section{Background}

Lumbar disc degeneration (LDD) is one of the most frequently diagnosed spinal diseases. The symptoms these disorders cause are anticipated to increase as the population in Western countries ages.

Purpose

Compare back and leg pain alleviation in patients with LDD and a viscoelastic disc prosthesis documented in the SWISSspine registry versus patients with anterior lumbar interbody fusion documented in the Spine Tango registry.

\section{Study Design}

Prospectively collected clinical and outcome data in two independent spine registries. Outcome Measures were back and leg pain relief on 0 to 10 numerical rating scales.

\section{Materials and Methods}

The analysis included a single surgeon series of 48 patients with viscoelastic total disc replacement (VTDR) from the SWISSspine registry which were compared to 131 patients with anterior lumbar interbody fusion (ALIF) from the Spine Tango registry.

Two linear multivariate regression models were built to assess the associations of patient characteristics with back and leg pain relief. The following covariates were included in the models: patient age and sex, disc herniation as additional diagnosis, number of treated segments, level of treated segment, treatment type (VTDR, ALIF), preoperative back and leg pain levels and follow-up interval.

Results

Both models showed VTDR to be associated with significantly higher back (2.76 points; $95 \%$ confidence interval (CI) 1.78 - 3.73; $\mathrm{p}<0.001)$ and leg pain $(2.12$ points; $95 \%$ CI 1.12 to 3.13; $\mathrm{p}<0.001)$ relief than ALIF. Other influential factors for higher back pain relief were female sex compared with male sex (1.03 additional points; 95\% CI 0.27 to $1.78 ; \mathrm{p}=0.008$ ), monosegmental surgery compared with bisegmental surgery (1.02 additional points; 95\% CI 0.21 to $1.83 ; \mathrm{p}=0.014)$, and higher back pain at baseline ( 0.87 points additional pain relief per level of preoperative back pain; $95 \%$ CI 0.70 to $1.03 ; \mathrm{p}<0.001)$. Other influential factors for leg pain relief were monosegmental surgery ( 0.93 additional points; $95 \% \mathrm{CI} 0.10$ to $1.77 ; \mathrm{p}=0.029)$ and higher leg pain at baseline ( 0.83 points additional pain relief per level of preoperative leg pain; $95 \% \mathrm{CI} 0.70$ to 0.96 ). In both models the L3/4 segment showed 2.36 points (95\% CI -4.27 to $-0.45 ; \mathrm{p}=0.016$ ) and 3.69 points (95\% CI -5.66 to $-1.71 ; \mathrm{p}<0.001$ ) less pain relief than L5/S1.

\section{Discussion}

Significantly higher back and leg pain relief were observed after viscoelastic total disc replacement in comparison with anterior lumbar interbody fusion. The new less rigid materials used in the second generation total disc replacements (TDRs) may make artificial disc replacement an increasingly attractive option for patients with 
degenerative lumbar disc disease. Further controlled and long-term follow-up studies are required for more detailed comparisons of the outcomes of these types of disc implants.

The Freedom Lumbar Disc is limited by U.S. federal law to investigational use only.

KEYWORDS: LUMBAR DISC DEGENERATION, LUMBAR DISC HERNIATION, VISCOELASTIC DISC, FREEDOM LUMBAR DISC, SPINE REGISTRY, SPINE TANGO, SWISSSPINE, COMPARATIVE EFFECTIVENESS RESEARCH

VOLUME 9 ARTICLE 26 DOI: 10.14444/2026

\section{Introduction}

Lumbar disc degeneration (LDD) is among the most frequent spinal pathologies today. The symptoms caused by LDD will likely continue to increase, as the population in Western countries has an increasingly higher life expectancy.

Fusion of the lumbar segments and total disc replacement are common surgical treatments for lumbar disc degeneration. Fusion surgery is performed via posterior, anterior or combined antero-posterior surgical approaches and may include a stand-alone cage, additional rigid stabilization or a rigid stabilization alone. Total disc replacement (TDR) as a motion preserving surgical concept has been increasingly used in the last decade, ${ }^{1,2}$ but it has not yet been adopted on a large scale. ${ }^{2}$ Various comparisons between different fusion and TDR types have been published in the literature. ${ }^{2}$ Recent long-term results of a randomized, multicenter U.S. Food and Drug Administration (FDA) investigational device exemption (IDE) study of the ProDisc-L versus $360^{\circ}$ fusion by Zigler et al. demonstrated that patients in both groups maintained significant improvement at least during the five postoperative years. ${ }^{3}$ The ProDisc group had a significantly better improvement in some scales. Although TDR patients avoided the stiffness of fusion and were more satisfied than fusion patients, both fusion and TDR are reasonable surgical options in this specific patient population according to the authors. ${ }^{3}$ The true comparator for the lumbar TDR is regarded to be anterior lumbar interbody fusion (ALIF) due to the similar surgical approach to the vertebral column and the solely anterior rigid or dynamic stabilization of the respective spinal segments. ${ }^{4}$

New generation disc implants attempt to better mimic the viscoelastic function of the natural discs with potentially more patient benefits in comparison to the "hard" first generation disc implants. They have been developed and introduced into clinical practice in recent years. ${ }^{5}$

Comparative effectiveness studies of different fusion types and TDRs are extremely rare today. ${ }^{4}$

Randomized clinical trials (RCT) comparing fusion and TDR are rare and have a high administrative burden. ${ }^{2}$ Wei et al. found six such RCTs in their meta-analysis, whereas only two trials used ALIF as comparator. ${ }^{2}$ Moreover, RCT results have high internal but lower external validity in contrast to observational effectiveness studies. Large registries like Spine Tango or SWISSspine represent optimal grounds for comparative effectiveness analyses using appropriate statistical methods. However, fusion and TDR may be used for specific and different patient populations in clinical practice, so that statistical matching could distort the true outcomes and their inter-relations.

The Freedom ${ }^{\circledR}$ Lumbar Disc (AxioMed LLC, Garfield Heights, OH, USA), consists of titanium alloy retaining plates with attached end caps, bonded to a viscoelastic, silicone polycarbonate urethane core. In the current analysis, back and leg pain relief are compared in patients with a new generation, viscoelastic disc replacement model who were documented in the SWISSspine registry against ALIF patients documented in the Spine Tango registry.

\section{Materials and Methods}

\section{Spine Tango Registry}

Data based on the three last versions of the surgeonbased form $(2005,2006$ and 2011) were used in the study. This form contains epidemiological and diagnostic data, treatment and surgical parameters, intraoperative details, complications, etc. The 
register allows this data to be linked to outcome data. Beyond the surgical records, patients are asked to complete a self-reported Core Outcome Measure Index (COMI) questionnaire with two numerical rating scales (NRS) of 0 to 10 points for back and leg pain. ${ }^{6}$

\section{ALIF from the Spine Tango Database}

The inclusion criteria for the ALIF group were: submitted form, disc degeneration with or without disc herniation as main diagnosis located in the segment L3-4, L4-5, or L5-S1, previous conservative treatment of at least three months, anterior interbody fusion between adjacent vertebrae with or without anterior rigid stabilization, as well as baseline and postoperative (3 - 30 months) COMI form. If multiple outcome forms were available for the patient, the last one was selected. Patients with spondylolisthesis, previous surgery, motion preserving measures or posterior approach were excluded.

\section{VTDR from the SWISSspine Registry}

The clinical data on the 48 patients were collected within a mandatory national registry for total disc replacement in Switzerland. Since the SWISSspine registry is a federally mandated quality and technology assessment project, no approval of the local ethics committee was required. However, an informed consent form is signed by each patient at the time of surgery. The detailed setup of SWISSspine has been previously reported. ${ }^{1}$ The registry is administered via the generic registry platform MEMdoc of the Institute for Evaluative Research in Medicine at the University of Bern. ${ }^{7}$ The registry is on-going since March 2005 and documents the surgeon- and patient-based data at baseline and at different follow-ups. As part of the patient-based outcome assessment the North American Spine Society (NASS) outcome instrument for the lumbar spine is used in the registry before and after surgery. ${ }^{1}$ The NASS instrument also has two NRS of 0 to 10 points, which is identical to the one in the Spine Tango COMI instrument. Follow-ups between 3 and 30 months were analyzed. If multiple patient forms were available the last data set was used in the analysis.

\section{Outcome Measures}

Outcome measures were back and leg pain relief in NRS points until the last available follow-up, with "responders" being defined as those achieving a minimum clinically important change (MCIC) of 2 points for axial and referred pain. ${ }^{8}$

\section{Statistical Analyses}

For the continuous outcomes, mean differences with standard deviation between VTDR and ALIF patients were calculated. In addition, different responder rates in the treatment groups were expressed as relative risks and $95 \%$ confidence intervals.

Two linear regression models were built to identify co-variates associated with back and leg pain relief, respectively. The following co-variates were included in the models: patient age (continuous), gender (male/female), disc herniation (yes, no), number of treated segments (monosegmental / bisegmental), treated segment (L3-4, L4-5, L5-S1), back (continuous) and leg pain (continuous) at baseline, treatment (VTDR, ALIF) and interval of follow-up (continuous). $\alpha$ was set to 0.05 throughout the study. All statistical analyses were conducted using SAS 9.4 (SAS Institute, Inc., Cary, NC, USA).

\section{Results}

The inclusion and exclusion criteria resulted in 48 VTDR and 131 ALIF patients. Their diagnostic and surgical characteristics are shown in Table 1.

The treatment groups were different for a number of characteristics except for the proportions of treated segments and for the follow-up interval (Table 1). In particular, bivariate comparison of the treatment groups showed significantly higher back and leg pain at baseline and significantly lower back and leg pain at the last follow-up in the VTDR group (Table 1, Figure 1).

The linear regression model on back pain relief adjusting for patient and treatment characteristics revealed patient sex, number of segments, treated segment, back pain at baseline, and treatment type to be associated with the extent of back pain relief 
(Table 2). According to the model, female patients had 1.03 points higher back pain relief $(95 \%$ confidence interval $(\mathrm{CI}) 0.27-1.78 ; \mathrm{p}=0.008)$ than male patients, monosegmental surgery had 1.02 points higher back pain relief $(95 \%$ CI $0.21-1.83 ; \mathrm{p}=$ 0.014 ) than bisegmental surgery, L3-4 had 2.36 points lower back pain relief (95\% CI -4.27 - $-0.45 ; \mathrm{p}$ $=0.016$ ) than L5-S1, and VTDR had 2.76 points higher back pain relief $(95 \%$ CI $1.78-3.73$; $p<0.001)$ than ALIF. Moreover, as anticipated and previously shown, ${ }^{1}$ every additional NRS point in back pain at baseline lead to a 0.87 points higher back pain relief (95\% CI $0.70-1.03 ; \mathrm{p}<0.001)$ (Table 2).

The linear regression model on leg pain relief revealed number of segments, treated segment, leg pain at baseline, and treatment type to be associated

Table 1. Description of diagnostic and surgical characteristics in the treatment groups.

\begin{tabular}{|c|c|c|c|}
\hline Patient characteristics & VTDR & ALIF & $\begin{array}{r}\text { Comparison } \\
\text { [p-value] }\end{array}$ \\
\hline $\mathrm{N}($ total $=179)$ & 48 & 131 & - \\
\hline Mean age (SD) [years] & $\begin{array}{r}49.1 \\
(12.5)\end{array}$ & $\begin{array}{l}45.1 \\
(9.3)\end{array}$ & 0.023 \\
\hline Female $[\%]$ & 43.8 & 71.8 & $<0.001$ \\
\hline Disc herniation [\%] & 66.7 & 23.7 & $<0.001$ \\
\hline Additional spinal pathology (\%) & - & 9.9 & - \\
\hline ASA unknown & - & 12.2 & \\
\hline ASA1 (\%) & - & 46.6 & \\
\hline ASA2 $(\%)$ & - & 40.5 & - \\
\hline $\mathrm{ASA}>2(\%)$ & - & 0.8 & \\
\hline Previous treatment 3-6mo. (\%) & - & 13.7 & - \\
\hline Previous treatment $6-12 \mathrm{mo} .(\%)$ & - & 19.9 & - \\
\hline Previous treatment $>12 \mathrm{mo} .(\%)$ & - & 66.4 & 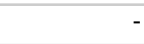 \\
\hline Bisegmental surgery [\%] & 56.3 & 21.4 & $<0.001$ \\
\hline Treated segment L3-4 [\%] & 2.1 & 3.8 & \multirow{3}{*}{0.64} \\
\hline Treated segment L4-5 [\%] & 27.1 & 21.4 & \\
\hline Treated segment L5-S1 [\%] & 70.8 & 74.8 & \\
\hline $\begin{array}{l}\text { Overall decompression performed } \\
(\%)\end{array}$ & 100.0 & 86.3 & 0.007 \\
\hline Discectomy (\%) & 100.0 & 86.3 & 0.007 \\
\hline Sequestrectomy (\%) & - & 8.4 & . \\
\hline Foraminotomy (\%) & - & 5.3 & - \\
\hline Osteotomy (\%) & - & 0 & . \\
\hline Laminotomy (\%) & - & 0 & 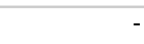 \\
\hline Hemilaminectomy (\%) & - & 0 & - \\
\hline Laminectomy (\%) & - & 0 & 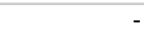 \\
\hline Facet joint resection partial (\%) & - & 0 & - \\
\hline Facet joint resection full (\%) & - & 0 & - \\
\hline Flavectomy (\%) & - & 0 & - \\
\hline Other type of decompression (\%) & - & 0 & - \\
\hline Back pain at baseline (SD) & $8.2(1.9)$ & $\begin{array}{r}6.9 \\
(2.2)\end{array}$ & $<0.001$ \\
\hline Leg pain at baseline (SD) & $7.1(2.9)$ & $\begin{array}{r}4.9 \\
(2.9)\end{array}$ & $<0.001$ \\
\hline $\begin{array}{l}\text { Average follow-up interval (SD) } \\
\text { [months] }\end{array}$ & $\begin{array}{l}16.4 \\
(8.9)\end{array}$ & $\begin{array}{l}14.5 \\
(8.0)\end{array}$ & 0.20 \\
\hline
\end{tabular}

with the extent of leg pain relief (Table 3 ). According to the model, monosegmental surgery had 0.93 points higher leg pain relief $(95 \% \mathrm{CI} 0.10-1.77 ; \mathrm{p}=$ $0.029)$ than bisegmental surgery, L3-4 had 3.69 points lower leg pain relief (95\% CI -5.66 - -1.71; p < $0.001)$ than L5-S1, and VTDR had 2.12 point higher leg pain relief $(95 \%$ CI $1.12-3.13$; p < 0.001) than ALIF. Furthermore, expectedly, every additional
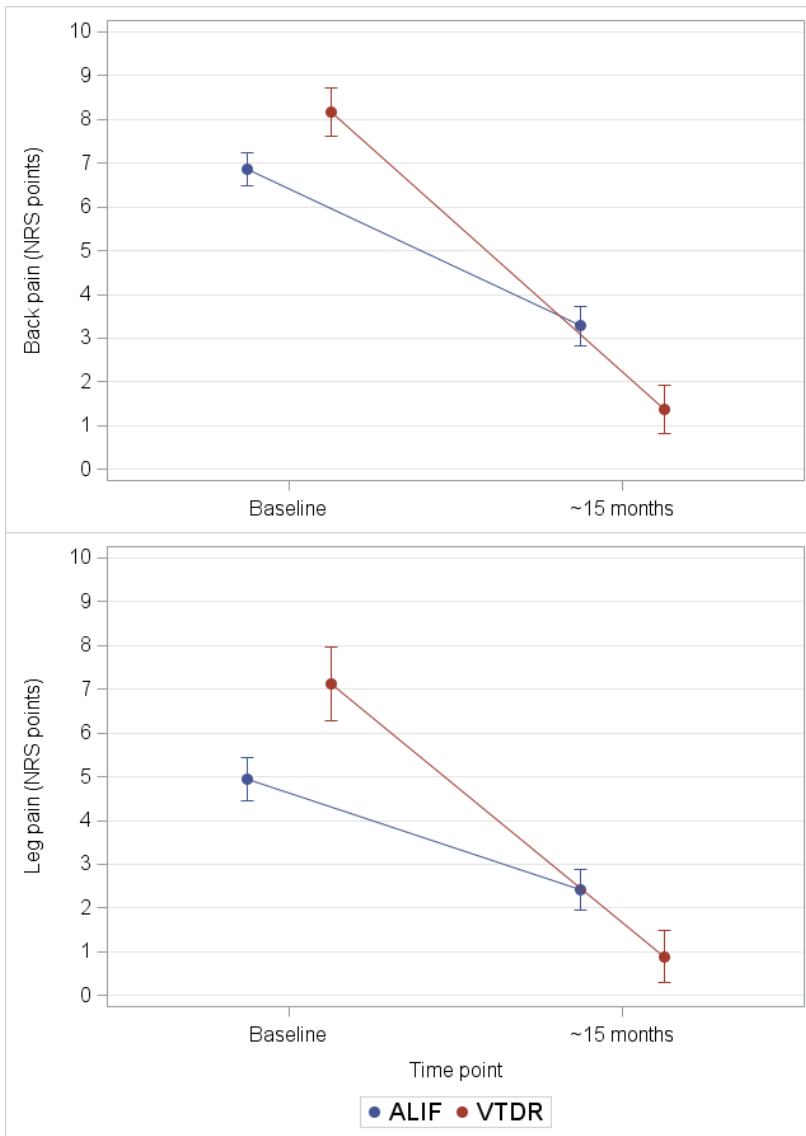

Fig. 1. Course of back and leg pain until last follow-up.

Table 2. The linear regression model on back pain relief.
\begin{tabular}{|l|r|r|r|r|r|}
\hline Co-variate & Effect & p-value & Estimate & $\begin{array}{r}\mathbf{9 5 \%} \text { confidence } \\
\text { intervals }\end{array}$ \\
\hline Age & per year & 0.94 & 0.00 & -0.04 & 0.03 \\
\hline Sex & female vs. male & $\mathbf{0 . 0 0 8}$ & $\mathbf{1 . 0 3}$ & $\mathbf{0 . 2 7}$ & $\mathbf{1 . 7 8}$ \\
\hline Disc herniation & no vs. yes & 0.87 & -0.07 & -0.87 & 0.74 \\
\hline $\begin{array}{l}\text { Number of } \\
\text { segments }\end{array}$ & $\begin{array}{r}\text { mono- vs. } \\
\text { bisegmental }\end{array}$ & $\mathbf{0 . 0 1 4}$ & $\mathbf{1 . 0 2}$ & $\mathbf{0 . 2 1}$ & $\mathbf{1 . 8 3}$ \\
\hline $\begin{array}{l}\text { Treated } \\
\text { segment }\end{array}$ & $\mathbf{L 3 - 4}$ vs. L5-S1 & $\mathbf{0 . 0 1 6}$ & $\mathbf{- 2 . 3 6}$ & $\mathbf{- 4 . 2 7}$ & $\mathbf{- 0 . 4 5}$ \\
\hline $\begin{array}{l}\text { Back pain at } \\
\text { baseline }\end{array}$ & per point & $<\mathbf{0 . 0 0 1}$ & $\mathbf{0 . 8 7}$ & $\mathbf{0 . 7 0}$ & $\mathbf{1 . 0 3}$ \\
\hline $\begin{array}{l}\text { Leg pain at } \\
\text { baseline }\end{array}$ & per point & 0.25 & -0.07 & -0.20 & 0.05 \\
\hline Treatment & VTDR vs. & $<\mathbf{0 . 0 0 1}$ & $\mathbf{2 . 7 6}$ & $\mathbf{1 . 7 8}$ & $\mathbf{3 . 7 3}$ \\
\hline $\begin{array}{l}\text { Follow-up } \\
\text { interval }\end{array}$ & per month & 0.27 & 0.02 & -0.02 & 0.07 \\
\hline Co-variates associated with the back pain relief are bold. & & -0.44 & 1.22 \\
\hline
\end{tabular}

Downloaded from http://ijssurgery.com/ by guest on April 26, 2023 
NRS point in leg pain at baseline lead to 0.83 points higher leg pain relief (95\% CI $0.70-0.96)$ (Table 3$)$.

\section{Minimum Clinically Important Changes}

At the average follow-up time of about 1.3 years the probability of being a responder (achieving MCIC) with regard to back pain relief was $93.8 \%$ after VTDR and $74.8 \%$ after ALIF (RR 1.25; 95\% CI 1.11 - 1.42; p $=0.005)$; for leg pain relief, the rates were $85.4 \%$ and $57.3 \%$, respectively (RR 1.49; 95\% CI $1.24-1.80 ; \mathrm{p}=$ $0.005)$.

\section{Discussion}

Comparative effectiveness studies of spinal fusion versus total disc arthroplasty are needed since fusion and motion preservation treatments may be applied to patients with the same diagnosis, which is degenerative disc disease unresponsive to conservative treatment. There is consensus that surgical treatment of these patients generally shows good outcomes when all conservative measures have failed. ${ }^{9-12}$

In our bivariate, non-adjusted comparisons, patients with VTDR achieved the minimum clinically relevant change of two points in back and leg pain relief $19 \%$ and $28 \%$ more frequently than patients with fusion, which was statistically significant and can also be deemed clinically relevant.

To account for potential selection bias and adjust for heterogeneity in the measured characteristics at baseline, a multivariate linear regression analysis was

\begin{tabular}{|c|c|c|c|c|c|}
\hline \multirow{2}{*}{$\begin{array}{l}\text { Co-variate } \\
\text { Age }\end{array}$} & \multirow{2}{*}{$\begin{array}{r}\text { Effect } \\
\text { per year }\end{array}$} & \multirow{2}{*}{$\begin{array}{r}\text { p-value } \\
0.57\end{array}$} & \multirow{2}{*}{$\begin{array}{r}\text { Estimate } \\
-0.01\end{array}$} & \multicolumn{2}{|c|}{$\begin{array}{r}95 \% \text { confidence } \\
\text { intervals }\end{array}$} \\
\hline & & & & -0.05 & 0.03 \\
\hline Sex & female vs. male & 0.66 & 0.17 & -0.61 & 0.95 \\
\hline $\begin{array}{l}\text { Disc } \\
\text { herniation }\end{array}$ & no vs. yes & 0.68 & -0.17 & -1.00 & 0.66 \\
\hline $\begin{array}{l}\text { Number of } \\
\text { segments }\end{array}$ & $\begin{array}{l}\text { mono- vs. } \\
\text { bisegmental }\end{array}$ & 0.029 & 0.93 & 0.10 & 1.77 \\
\hline \multirow{2}{*}{$\begin{array}{l}\text { Treated } \\
\text { segment }\end{array}$} & L3-4 vs. L5-S1 & $<0.001$ & -3.69 & -5.66 & -1.71 \\
\hline & L4-5 vs. L5-S1 & 0.31 & 0.44 & -0.42 & 1.30 \\
\hline $\begin{array}{l}\text { Back pain at } \\
\text { baseline }\end{array}$ & per point & 0.83 & 0.02 & -0.15 & 0.19 \\
\hline $\begin{array}{l}\text { Leg pain at } \\
\text { baseline }\end{array}$ & per point & $<0.001$ & 0.83 & 0.70 & 0.96 \\
\hline Treatment & $\begin{array}{r}\text { VTDR vs. } \\
\text { ALIF }\end{array}$ & $<0.001$ & 2.12 & 1.12 & 3.13 \\
\hline $\begin{array}{l}\text { Follow-up } \\
\text { interval }\end{array}$ & per month & 0.99 & 0.00 & -0.04 & 0.04 \\
\hline
\end{tabular}

used. Patient age, sex, number of segments, treated segment, additional disc herniation, baseline back and leg pain, and interval to follow-up were included. The potentially varying proportions of ASA based patient morbidity, durations of previous treatment and decompression types could not be considered in the adjustments, as these data are not part of the dataset in the SWISSspine registry and were not available for the VTDR group. This fact limits the explanatory power of the results and requires further studies, but it can be postulated that few to no patients with ASA classes $>2$ would receive instrumented dynamic or rigid stabilization and that both samples are hence rather homogeneous with a domination of ASA 1 and 2 patients.

Based on the study results, it can be stated that in patients with disc degeneration with or without disc herniation, besides patient sex, number of the treated segments and the treated segment itself, as well as the preoperative status of the respective outcome, the treatment type was significantly associated with the extent of back and leg pain relief. It was at least 2.1 NRS points higher than in ALIF patients. The influence of the preoperative pain status on the respective outcome is a known phenomenon. ${ }^{1}$

The segment L3-4 was treated in about $2 \%$ of the VTDR and $4 \%$ of the ALIF patients. In those cases, the regression models revealed lower pain relief of at least 2.4 NRS points in comparison to other, distal lumbar segments. This segment also showed relatively high revision rates in previous analyses. ${ }^{13}$

Furthermore, monosegmental surgery appears to lead to an up to $1 \mathrm{NRS}$ point higher pain relief than bisegmental surgery. We believe that this finding may be attributable to generally worse conditions of patients with multiple affected levels. A recent Spine Tango analysis has also revealed higher numbers of the treated segments to negatively influence patient outcomes after lumbar spinal stenosis surgery. ${ }^{14}$

Interestingly, female sex was associated with a 1 NRS point higher back pain relief in the study, which is rather unexpected and might have been caused by confounding variables. An influence of other, unobserved factors may not be excluded in our study

Downloaded from http://ijssurgery.com/ by guest on April 26, 2023 
- it should rather be hypothesized as the adjustment co-variates were limited in our study.

The value of lumbar total disc arthroplasty is still controversially debated, although several high quality studies with intermediate follow-up have proven the usefulness of this procedure, its non-inferiority or superiority to lumbar fusion in selected patients, and its safety regarding reoperations or complications. ${ }^{3,15-17}$ Also, cost-effectiveness compared with fusion was repeatedly shown. ${ }^{18-20}$ An RCT by Zigler et al. demonstrated that patients treated with either circumferential arthrodesis or TDR maintained significant improvements until five years after surgery. ${ }^{3}$ The authors stated that despite TDR patients avoiding the stiffness of fusion and being more satisfied than fusion patients, both fusion and TDR were reasonable surgical options. Similarly, the RCT by Guyer et al. showed no significant differences between TDR and ALIF, except for a significantly greater rate of part- and full-time employment and a significantly lower rate of longterm disability in TDR patients. ${ }^{15}$ A recent RCT of TDR versus posterior and posterolateral fusion techniques with highly selected patients showed significantly better results for most of the outcomes in favor of TDR patients. ${ }^{17} \mathrm{~A}$ recent matched comparison of pain alleviation of all lumbar TDRs in the SWISSspine registry with ALIF cases from the Spine Tango registry showed similar results. ${ }^{4}$ The 5-year results of 248 lumbar TDRs in the SWISSspine registry showed significant and longlasting back and leg pain relief from 7.2 and 5.5 Visual Analog Scale (VAS) points preoperative to 2.8 and 2.2 points postoperative at the fifth postoperative year. ${ }^{13}$ It should be noted that the implants used in this study were implanted in the years 2005 and 2006 and still represent the first generation of lumbar disc arthroplasties. An even further alleviated back and leg pain with compliant second generation lumbar disc prosthesis like VTDR may be potentially well explained by further improvement of disc prosthesis design and material properties, instrumentation, improved and stricter patient selection and comprehensive surgical experience. However, these are speculations, and further comparative studies between second generation TDR prostheses and alternative types of spinal treatments are needed, especially with midand long-term follow-up.

\section{Limitations}

One important limitation of the current analysis requires mention. The patients had different numbers of follow-ups and different follow-up intervals that required use of the latest available follow-up per patient between 3 and 30 months postoperative. The average latest available follow-up was 1.3 years, and the follow-up interval needed adjustment in the statistical models.

\section{Conclusions}

In patients with disc degeneration with or without disc herniation, viscoelastic total disc replacement showed a higher likelihood for the achievement of clinically relevant back and leg pain relief than anterior lumbar interbody fusion. Also, significantly higher absolute back and leg pain relief were observed in the VTDR group. Other factors associated with higher pain relief were higher number of treated segments, more distal lumbar segment, and higher pain level at baseline. Further controlled and long-term follow-up studies are required for more detailed comparisons between next generation, viscoelastic disc implants and anterior lumbar interbody fusion.

\section{References}

1. Schluessmann E, Diel P, Aghayev E, Zweig T, Moulin P, Roder C (2009) SWISSspine: a nationwide registry for health technology assessment of lumbar disc prostheses. Eur Spine J 18:851-861.

2. Wei J, Song Y, Sun L, Lv C (2013) Comparison of artificial total disc replacement versus fusion for lumbar degenerative disc disease: a meta-analysis of randomized controlled trials. Int Orthop 37:1315-1325.

3. Zigler JE, Delamarter RB (2012) Five-year results of the prospective, randomized, multicenter, Food and Drug Administration investigational device exemption study of the ProDisc-L total disc replacement versus circumferential arthrodesis for the treatment of single-level degenerative disc 
disease. J Neurosurg Spine 17:493-501.

4. Aghayev E, Henning J, Munting E, Diel P, Moulin P, Roder C, Swissspine, Spine Tango

Registry g (2012) Comparative effectiveness research across two spine registries. Eur Spine J 21:1640-1647.

5. Rischke B, Ross RS, Jollenbeck BA, Zimmers KB, Defibaugh ND (2011) Preclinical and clinical experience with a viscoelastic total disc replacement. SAS Journal 5:97-107.

6. Mannion AF, Porchet F, Kleinstuck FS, Lattig F, Jeszenszky D, Bartanusz V, Dvorak J, Grob D (2009)

The quality of spine surgery from the patient's perspective: part 2. Minimal clinically important difference for improvement and deterioration as measured with the Core Outcome Measures Index. Eur Spine J 18 Suppl 3:374-379.

7. IEFO (2012) www.memdoc.org. University of Bern.

8. Ostelo RW, Deyo RA, Stratford P, Waddell G, Croft P, Von Korff M, Bouter LM, de Vet HC (2008) Interpreting change scores for pain and functional status in low back pain: towards international consensus regarding minimal important change. Spine (Phila Pa 1976) 33:90-94.

9. Amundsen $\mathrm{T}$, Weber $\mathrm{H}$, Nordal HJ, Magnaes B, Abdelnoor M, Lilleas F (2000) Lumbar spinal stenosis: conservative or surgical management?: A prospective 10-year study. Spine (Phila $\mathrm{Pa} 1976$ ) 25:1424-1435; discussion 1435-1426.

10. Weinstein JN, Tosteson TD, Lurie JD, Tosteson A, Blood E, Herkowitz H, Cammisa F, Albert T, Boden SD, Hilibrand A, Goldberg H, Berven S, An $H$ (2010) Surgical versus nonoperative treatment for lumbar spinal stenosis four-year results of the Spine Patient Outcomes Research Trial. Spine (Phila Pa 1976) 35:1329-1338.

11. Slatis $P$, Malmivaara A, Heliovaara M, Sainio P, Herno A, Kankare J, Seitsalo S, Tallroth K, Turunen V, Knekt P, Hurri H (2011) Long-term results of surgery for lumbar spinal stenosis: a randomised controlled trial. Eur Spine J 20:1174-1181.

12. Malmivaara A, Slatis $P$, Heliovaara M, Sainio $P$, Kinnunen H, Kankare J, Dalin-Hirvonen N, Seitsalo S, Herno A, Kortekangas P, Niinimaki T, Ronty H, Tallroth K, Turunen V, Knekt P, Harkanen T, Hurri H, Finnish Lumbar Spinal Research G (2007)

Surgical or nonoperative treatment for lumbar spinal stenosis? A randomized controlled trial. Spine (Phila Pa 1976) 32:1-8.

13. Aghayev E, Etter C, Barlocher C, Sgier F, Otten P, Heini P, Hausmann O, Maestretti G, Baur M, Porchet F, Markwalder TM, Scharen S, Neukamp M, Roder C (2014) Five-year results of lumbar disc prostheses in the SWISSspine registry. Eur Spine J 23:2114-2126.

14. Sobottke R, Herren C, Mannion AF, Röder C, Aghayev E (2015) Predictors of improvement in quality of life and pain relief in lumbar spinal stenosis relative to patient age: a study based on the Spine Tango registry. Eur Spine J conditionally accepted. 15. Guyer RD, McAfee PC, Banco RJ, Bitan FD, Cappuccino A, Geisler FH, Hochschuler SH, Holt RT, Jenis LG, Majd ME, Regan JJ, Tromanhauser SG, Wong DC, Blumenthal SL (2009) Prospective, randomized, multicenter Food and Drug Administration investigational device exemption study of lumbar total disc replacement with the CHARITE artificial disc versus lumbar fusion: fiveyear follow-up. Spine J 9:374-386.

16. McAfee PC, Cunningham B, Holsapple G, Adams K, Blumenthal S, Guyer RD, Dmietriev A, Maxwell JH, Regan JJ, Isaza J (2005) A prospective, randomized, multicenter Food and Drug Administration investigational device exemption study of lumbar total disc replacement with the CHARITE artificial disc versus lumbar fusion: part II: evaluation of radiographic outcomes and correlation of surgical technique accuracy with clinical outcomes. Spine (Phila Pa 1976)

30:1576-1583; discussion E1388-1590.

17. Skold C, Tropp H, Berg S (2013) Five-year follow-up of total disc replacement compared to fusion: a randomized controlled trial. Eur Spine J. 18. Guyer RD, Tromanhauser SG, Regan JJ (2007) An economic model of one-level lumbar arthroplasty versus fusion. Spine J 7:558-562.

19. Kurtz SM, Lau E, Ianuzzi A, Schmier J, Todd L, Isaza J, Albert TJ (2010) National Revision Burden for Lumbar Total Disc Replacement in the United States: Epidemiologic and Economic Perspectives. Spine (Phila Pa 1976).

20. Levin DA, Bendo JA, Quirno M, Errico T, Goldstein J, Spivak J (2007) Comparative charge analysis of one- and two-level lumbar total disc 
arthroplasty versus circumferential lumbar fusion. Spine (Phila Pa 1976) 32:2905-2909.

\section{Disclosures}

Burkhard Rischke declares no relevant financial disclosures; Kari Zimmers and Eric Smith are employees of AxioMed LLC.

\section{Corresponding Author}

Kari B. Zimmers, B.S., AxioMed LLC, 5350
Transportation Blvd., Suite 18, Garfield Heights, OH 44125, USA. karizimmers@gmail.com

Published 1 July 2015.

This manuscript is generously published free of charge by ISASS, the International Society for the Advancement of Spine Surgery. Copyright ๑ 2015 ISASS. To see more or order reprints or permissions, see http://ijssurgery.com. 